\title{
CLOUD LIBRARY SERVICES: A POSITIVE THINKING FOR SMART LIBRARIAN
}

\author{
Soma Prasad \\ Student of MLISc, IGNOU, India \\ Dr. Shyamal Ghosh \\ Librarian, Academy of Technology, \\ Adisaptagram, Hooghly, India
}

\begin{abstract}
Cloud Computing is most important part in our modern tech-savvy society. Cloud library services are also support the society. In our paper we discuss cloud computing and its architecture, cloud library and its services, and the implementation areas of cloud by the tech-smart librarian.
\end{abstract}

Key words: Cloud Computing; Cloud Library, Cloud Library Services

Cite this Article: Soma Prasad and Dr. Shyamal Ghosh, Cloud Library Services: A Positive Thinking for Smart Librarian, International Journal of Library \& Information Science, 8(3), 2019, pp. 61-69.

http://www.iaeme.com/IJLIS/issues.asp?JType=IJLIS \&VType=8\&IType=3

\section{INTRODUCTION}

Cloud computing is the latest technological trend in library science for various services. Cloud Library allows avoiding locally hosting multiple services and equipments and constantly dealing with hardware failure, software install and update, and compatibility issues etc. Many libraries using cloud computing for simplified processes and save time and money. Library have been using some cloud computing services like Union Catalogue, Online databases etc. Cloud computing solution can create the new workforce needed by smart librarian because it offers the opportunity for co-operative platform for libraries to build on.

\subsection{Review Literature}

Basic aim to any librarian to involvement their service which based on cloud. Here we studies some of the scholar view. Mate (2016) express in his studies that newly develop area known as Cloud Computing and how the concept of cloud computing apply in the library services. The emerging trends of digital libraries, e- publications, web based tools, internet, library network and consortium practices leads to the development in library services. Margaret (2013) survey and discus the concept of cloud based library management system for cost effective library automation. He also focuses on analytical discussion on various open source 
library automation software. Mandal (2013) describe that there are different forms of cloud computing. He express on three form of cloud computing such as how service, platform or infrastructure form of cloud computing have been used to serve different library needs and also focus on the Methodology of development of cloud computing in integrated library Management system. Nandkishor Gosavi (2012) discuss about the newly development area known as cloud computing, use of computing and how actually cloud computing works in library and also describe a brief history of cloud computing along with characteristics and their benefit in libraries. Bombale (2014) deals with the use of modern concept and technologies to make the management task easier and effective and helpful not only in cost management but also solving the space problem in libraries. Ruhela (2018) deals with the theoretical concept of cloud computing and its implementation in library and information system. Cloud computing offer libraries to provide their services in web based environment. The main purpose of this paper is to explore the cloud computing system, their types, possible area, its advantages or disadvantages etc. Alotaibi (2013) focuses on the utilisation of cloud computing in library and information centres. This study deals with the various aspects of uses of cloud computing in libraries, model of cloud computing, essential characterstics, its benefit, how the trend of cloud computing will be impact on libraries. Nagalakshmi (2013) describe in his paper impact of cloud computing at libraries. It provide an idea about the activities at library with cloud computing. it also focus the cloud computing initiatives. Cloud computing may help libraries to undertake modern ICT activities without worrying about technical side of it, except adding content of resources. So, it makes a big difference ICT world. Das (2013) explain some basic idea to choose or evaluate cloud services for the libraries. Before putting any data on cloud and using server of cloud it is necessary to know the advantages and disadvantages of the sevices of cloud computing. This paper provide a brief knowledge about advantages and disadvantages of cloud computing. Wada (2018) focuses on the implementation of cloud computing in the library, requirements that are necessary in the library for proper implementation of cloud computing in the library.

\section{CLOUD: CONCEPT, MODEL AND ARCHITECTURE}

Cloud is a new concept for delivery of application software through internet instead of installing and running the same on a user's computer. The software is running remotely on a web server somewhere and the user access the application using only a web browser. Cloud has brought a new revolution in the IT world for use of software and leading organisations across the globe are switching over to cloud model from the traditional model for use of software. Cloud remove the services like installation, deployment, support, maintenance, upkeep, virus control, regular backup security etc. Cost of all such services, though unseen, forms a major part of the operational cost. Since the software and data are not stored on user's computer, user does not require large data storage facilities. Cloud provides 24 hours services. The user can access the application like ubiquitous form from anywhere at any time.

\subsection{Models of Cloud Computing}

Cloud computing is basically the use of computing resources i.e. hardware and software that are provide as a services over a network. Two models are working for the cloud computing i.e., Cloud service model and Cloud Deployment model

\subsubsection{Cloud Service model}

The cloud service models are 


\subsubsection{Infrastructure as a Service (IaaS)}

This service model provides access to fundamental infrastructure such as virtual machine and storage, IP address etc. It enhanced scalability and provide flexibility. The cloud customer can be provided a freedom to install or develop its own operating system like linux, unix, ubuntu etc. All these services are made available to the customer via server virtualisation.

\subsubsection{Platform as a service (PaaS)}

Platform as a service model provide the suitable run time environment to develop the application or software. It also provides development and deployment tools, programming languages that are required to develop application. It is mainly used by developers. No need to purchase expensive software and hardware to develop any application, the only requirement is well trained developers who have the knowledge of programming language and the high speed internet to use platform as a service model. It provide the tools and services designed to make coding and deployment those application quick and efficient.

\subsubsection{Software as a service (SaaS)}

This model is mainly used by end users or non technical background persons. It provides software application as a service to the end users. It refers to software that is deployed on a hosted service and it accessible via internet from any online device. Some of the web based application are free such as google apps, skype etc while some of the application on SaaS are on subscription basis. Software as a service model provide little customisation or control available with these application. The end users enjoy the facility of low initial cost; 24 hours support service, and need not tension about hosting, installing, upgrading, and maintaining the software.

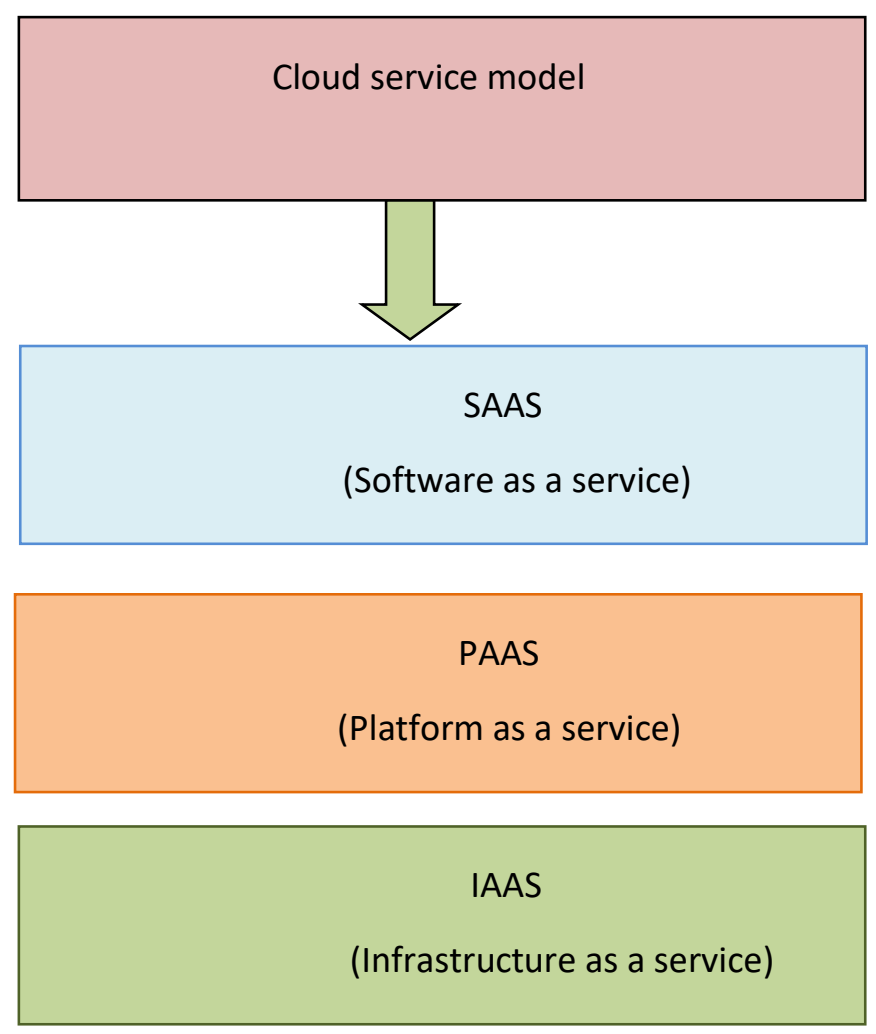

Figure 1 Cloud Service Model 


\subsubsection{Cloud Deployment model}

Deployment models refer to the type of access to the cloud such as how cloud is located. Cloud computing can be divided into four types of deployment model on the basis of location where the cloud is hosted. These are as follows:-

\subsubsection{Public cloud model}

The public cloud model as the name suggested allows services and system to be accessible to all general public. The whole cloud computing infrastructure is fully controlled by the third party provider. Common examples of cloud service provider are Microsoft, google, Amazon etc.

\subsubsection{Private Cloud Model}

The private cloud model allows system and services to be accessible within organisation. It is only operated within a single organisation and managed internally by third party. These private cloud models provide more security because it is implemented within an internal firewall.

\subsubsection{Hybrid Cloud Model}

The hybrid cloud model is a mixture of public cloud model and private cloud model. Organisation hosts some critical, secure application in private clouds whereas not so critical applications are hosted in public clouds. An organisation uses the public cloud services along with its own cloud to perform resource intensive application.

\subsubsection{Community Cloud Model}

This cloud allows system and services to be accessible by group of organisation. Third party provider or member organisation can hold the responsibility of managing the cloud. It share the responsibilities between several organisation (Mate, 2016)

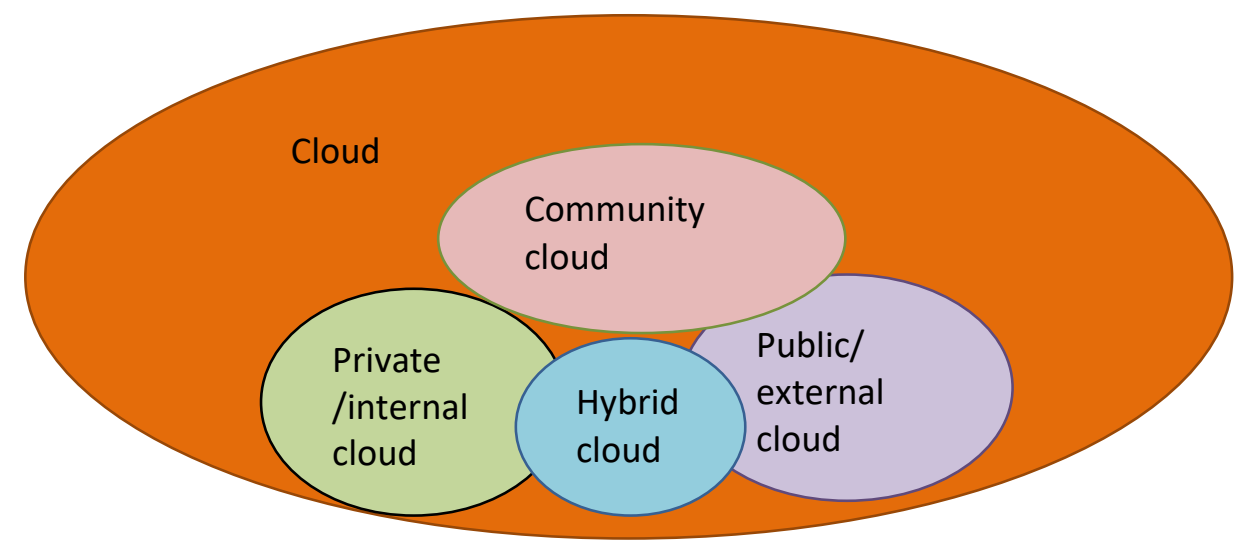

Figure 2 Cloud Deployment Models

\subsection{Architecture of Cloud Computing}

The cloud computing architecture comprises of many cloud component. Each of them loosely coupled and is independent. Cloud architecture may broadly divide into two parts i.e. Front End and Back End.

Front end of the cloud refers to the client part of the cloud computing system. It consists of interfaces and application that are required to access the cloud platform. Other hand Back end of the cloud refers to cloud itself. It is consist of huge data storage, security management, application servers, infrastructures, deployment models, virtual machine and so on. 


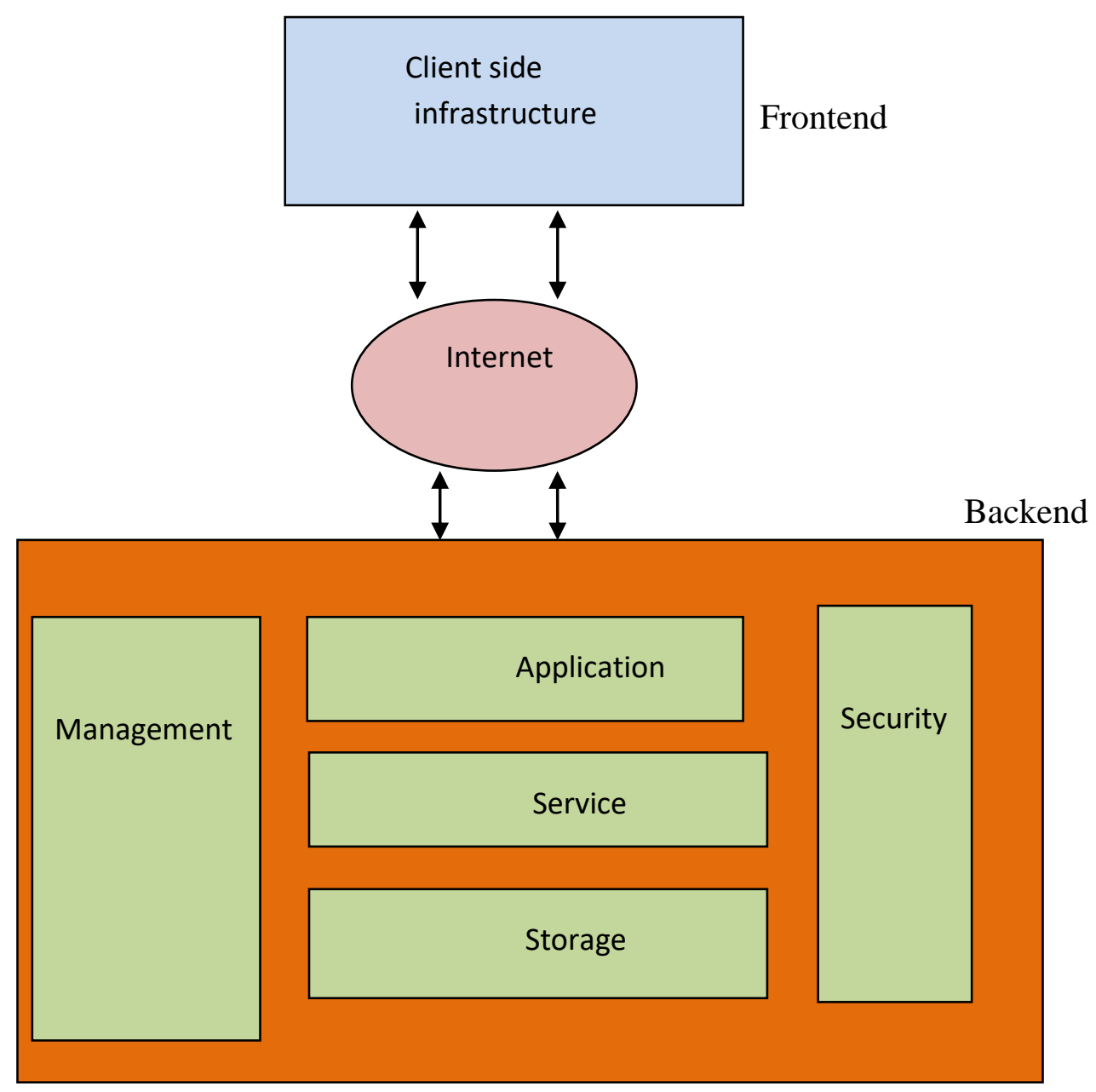

Figure 3 Graphical view of cloud computing architecture

\subsection{Benefit of Cloud}

i) Scalability: scalability is one of the most valuable and predominant features of cloud computing. It refers to ability of system or infrastructure to manage the growing load on internet. It can manage to scale up the data storage capacity or scale down to meet the demands of internet traffic.

ii) Reduced investments: Users only have to pay for the services Which they choose and thus this technology enables the libraries to save the cost of software infrastructure.

iii) Easy installation and maintenance: In cloud computing, there is no need to worry about server updates and other computing issues. IT staff of the organisation can focus on other critical issues rather than updating and maintaining software. There is no need to buy any hardware to run the server.

iv) Reliability: It is more reliable and consistent. It provides 24 hours services to their users. User from anywhere can access the data store in cloud and uses the services of cloud computing from anywhere and in anytime with strong internet connectivity.

v) Backup and Restoration: Cloud network can provide backup and restoration facilities with high security of document. Data in cloud are stored in different places of the world so if data stored in one place is lost or damage can be restore from the other places. 
vi) Increase storage: Storage capacity in cloud computing is extremely larger than any organisational network system. So, more data can be stored in cloud computing than any other organisational network system.

vii) Share resources: cloud computing provide the facility of exchange of data more effective and efficiently.

\section{CLOUD COMPUTING IN LIBRARY}

Cloud computing is a new type of services that offered over the internet. The concept of cloud computing has completely changed the way of using computers irrespective of geographical location. In library, information or data is growing very fast in the recent age and the usage of that information or data is also increased simultaneously. Cloud plays a most important role to provide a platform to store the information in one place that is in a common server and disseminate that information to the users as and when required via web based system. Some of the examples of cloud computing services in libraries are as follows:-

- Library automation with multiuser

- Web hosting

- Federated search via Web OPAC

- Universal OPAC

- ILS-LMS

- Online resource sharing

- Digital Library

- Interlibrary loan etc.

\subsection{Area of Implementation of Cloud Computing in Library}

In the digital era, library also needs to be smart in their structure, infrastructure and services in order to fulfil the growing demands of their users instantly. Because, library is capable to make the information resources available seamlessly, then only library patron can be provided the relevant information quickly and easily. A library is said to be smart when it has certain facilities like internet access, digital resource, computers and laptops and other IT facilities. To implement cloud computing, following facilities must be available in the library system then cloud computing can be implement successfully. If any one of them will be missing then it will be difficult or say impossible to implement cloud computing in library. Therefore the basic requirements are as follows:

a) High speed internet access: Internet services play a most important role through which resources can be accessed, shared and distributed among different people across the world. Library can only access the cloud computing resources if it has high speed internet facility. Therefore high speed internet facility is considered to be the most vital factor while implementing cloud computing in the library.

b) Thin client architecture: Most important requirement to implement cloud computing in the library is thin client architecture. In the thin client architecture, multiple computers having keyboard, mouse, desktop can be operated by one single CPU with the help of thin client. No. of computers added depends on the capacity of the harddisk or RAM of the CPU of server. The accesses on the client computer are totally controlled by the Server.

c) Wireless Access point: Wireless access point is the platform that transmits and receives data wirelessly within a LAN. It connects users to the server within a network such as Wi Fi. Library patrons can use the wireless technology in the library to access the resources of the cloud. 
d) Digital Resource: Digital resources in the library are the information resources in an electronic form or resources that are converted into digital form. It is important to digitised the library resources for their proper storage in the cloud or using digital library software in cloud and easily accessible to the users.

e) Smart Cloud Librarian: For the proper implementation of cloud computing in the library, personnel having knowledge of IT, adequate knowledge related to system installation, hardware, networking and internet management are required for managing client-server architecture and wire-less access point. Beside of that he/she must have quality of content management.

Now the following possible fields were identified where cloud computing services and application may be applied:

i) Digital library system: Digital library is the need of the present era. Libraries digitized their resources and place in a network to provide flexibility that means everyone from anywhere can access the resource easily and effectively. For developing a digital library, digital library software is required. Now Dspace and Fedora are used for developing digital libraries and repositories. Dura cloud provides complete solution for developing digital libraries and repositories with standard interface and open source codes for both the software.

ii) Cloud hosting: This is one of the earliest adoptions of cloud computing. Many organisations preferred to host their website on third party service providers rather than hosting and maintaining their own server, libraries are also not outside from this scenario. Adding the website to internet needs two basic things first one is domain name and second one is web hosting. Domain name is the IP address of the website on the internet and website hosting is the storage area on the internet in which all data that are uploaded in the website will be stored. Cloud computing as compared to dedicated server or shared hosting is much cheaper and highly secure. Library website can be added to internet through cloud hosting. Cloud hosting provide unlimited bandwidth, full security, unlimited storage, no risk of server failure as data is store in multiple server in cloud, cost effective, scalability.

iii) Sharing library data: Data of the library must be shared for their effective use. Cloud computing provide the platform to share their data. OCLC is one of the best examples for making use of cloud computing for sharing libraries data. OCLC also provide various services like circulation. Cataloguing, acquisition and other library related services on cloud platform through web share management system.

iv) File storage: The main function of any library is to store their resources and provide their access to their patrons. Cloud computing provide number of services such as Google Doc, Sky drive, flicker, Drop box etc to access many files on the internet. These services provide virtual sharing of the files on the web and access to those files from anywhere and in anytime without any need of special software and hardware.

v) Web OPAC: Network libraries can use same platform and give access to their collection on one platform. Through cloud computing creation of union catalogue becomes very easy.

vi) Community power (network building): Community power plays a important role to build a network of communication between library and information science professional and information seekers. Cloud computing technology provides a great facility to build such network among them. Some of the popular social networking service which plays a very important role in building community power like facebook, twitter, instagram etc.

These cooperative efforts of libraries will save time provide efficiencies and wider recognition, cooperative intelligence for better decision making. It also provides the platform for sharing the information and knowledge. 
vii) Integrated library management: Library automation helps the librarians and other library staff to reduce some of their workload mainly in the areas of acquisition, cataloguing and circulation. Integrated library management help libraries to perform better function and serve to their users. Saved time can be used to perform various functions in the library and make library staff available to solve the different queries of their users and also make available to answer the reference question.

viii) Library RFID System: Radio Frequency identification playing a important role in modern identification technique. RFID uses radio frequencies to identify a particular object and differentiate them from others. Modern library started using RFID technique to provide security to their document. It is very reliable and efficient. By making a system of RFID, cloud and ARM 11, library can provide more security and provide effective library data management system. The system keep records of books, borrowers name, ID etc. By using RFID technology these data's are stored into cloud. The authenticated user can then access the information which is stored in the cloud by using their user ID or password.

\section{CONCLUSION}

Cloud Library service is most important of modern smart library because in ubiquitous era users are very high tech-savvy and their needs very heterogeneous. They do not have much more time to physical visit in the library. They have smart phone, just click on the button and get information very easily and quickly. If any library give that type of services and then users are satisfied then library must have cloud services and librarian should be smart librarian in the present information dissemination era.

So, Cloud libraries have the opportunity to improve their services and relevance in today's tech-society. Cloud Computing is one of the best way for this move into the future. It can bring said above several benefits for libraries and given them modern cloud tech-savvy information society with the help of smart tech-librarian.

\section{REFERENCES}

[1] Alotaibi, M. S. (2013). Utilisations of Cloud Computing in Library and Information Centers: A Theoretical Study. Internation Journal of Digital Library Services , 3 (4), 8393.

[2] Bombale, S. R. (2014). Implementation of Cloud Technology for Remote Data Access for Library Management using ARM11. International Journal of Computer Application , 99 (9), 15-19.

[3] Das, D. S. (2013). Application of cloud computing in Digital library Advantages \& Disadvantages. Asian Academic Research Journal of Multidisciplinary, 1 (3), 226-234.

[4] Mandal, A. k. (2013). Development of Cloud Computing in integrated llibrary management and retrieval system. International Journal of Library and Information Science, 5 (10), 394-400.

[5] Margaret, G. C. (2013). Library Automation in Cloud. 5th International Conference on Computational Intelligence and Communication Networks, (pp. 474-479).

[6] Mate, K. S. (2016). Use of Cloud Computing in Library Services. International Journal of Engineering Science and Computing , 6 (5), 4693-4697. 
[7] Nagalakshmi, L. R. (2013). Application of Cloud Computing at library and information centers. The International Journal's Research Journal of Science \& IT Management , 2 (5), 43-46.

[8] Nandkishor Gosavi, S. S. (2012). Use of Cloud Computing in Library and Information Science Field. International Journal of Digital Library Services , 2 (3), 51-60.

[9] Ruhela, A. u. (2018). Implementation of Cloud Technology in Library and Information System. Internation Journal of Library and Information Management , 9 (1), 10-14.

[10] Wada, I. (2018). Cloud Computing implementation in librarires: A Synergy for library services optimization. International Journal of Library and Information science , 10 (2), $17-27$.

[11] www.cybrarian.in/Default.aspx. (n.d.). Retrieved from www.cybrarian.in. On 20.11.2019. 